\title{
Competitiveness of dairy farms in northern Europe: A cross- country analysis
}

\author{
Xavier Irz ${ }^{1}$ and Csaba Jansik ${ }^{2}$ \\ ${ }^{1}$ Natural Resources Institute Finland (Luke), Economics \& Society Research Unit, Latokartanonkaari 9, 00790 Helsinki, Finland \\ ${ }^{2}$ LUKE Natural Resources Institute, Latokartanonkaari 9, 00790 Helsinki, Finland \\ e-mail: csaba.jansik@luke.fi
}

\begin{abstract}
The milk sector has received much attention in Europe due to the abolition of milk quotas in 2015 and its potential effect on the geographical distribution of milk production across countries. As a way of assessing the competitive advantage of Nordic EU countries, we investigated the productivity level and productivity growth of milk farms across eight countries of the Baltic Sea region from 1995 to 2010. We found considerable discrepancy in the productivity performance of dairy farms across countries. TFP growth rates indicate that, at farm level, the competitive positions of the older EU members are stable, and that there is no catching up from the newer EU entrants. We offer explanations for this evolution based on the different patterns of structural change followed by the studied countries.
\end{abstract}

Key words: productivity, TFP, Baltic Sea, efficiency, competitiveness indicator

\section{Introduction}

By any measure, Northern European countries of the Baltic Sea region account for a large share of EU dairy farming. Hence, according to Eurostat data, in year 2012 37\% of the volume of milk delivered to EU dairies originated from farms located in Germany, Denmark, Sweden, Finland, Estonia, Latvia, Lithuania and Poland, i.e. the eight EU countries of the Baltic Sea region forming the focus of this study. Further, in many of those countries, dairy farming is the mainstay of the agricultural sector, as it is particularly well suited to the agro-ecological conditions associated with relatively high latitudes, and those conditions also limit the number of viable alternatives in the agricultural sector. In the midst of changing markets and policies, ensuring the competitiveness of milk farming in Northern Europe therefore represents an important objective for the stakeholders of the dairy supply chain, including primary producers, processors, wholesalers, retailers, ordinary consumers, and policy makers (Drescher \& Maurer 1999). This idea is reinforced by the increased competition that is expected to follow the abolition of milk production quotas throughout the EU in 2015, as well as the challenges thrown by the recent Russian embargo on the importation of dairy products originating from the EU.

Against this background, this paper presents a comparative analysis of the farm-level competitiveness of the dairy sectors of the eight EU countries of the Baltic Sea region, with three specific objectives: 1 . To measure and compare farm-level competitiveness across countries. 2. To explain this evolution by identifying its main drivers. 3 . To draw the implications of this analysis for the evolution of the sector in the medium to long term.

While the concept of competitiveness has great intuitive appeal and is therefore widely used, it is important to define it at the outset to avoid any ambiguity in meaning. Following DEFRA (2002), we consider that competitiveness is achieved when individual firms within a sector are able to sell products at a price and quality that compare favourably to those of competitors. This uncontroversial definition already implies that competiveness is a relative concept, as emphasized by Latruffe (2010), which gives high relevance to a comparison across countries of a given region such as Northern Europe. Yet, the definition provides little guidance as to how competiveness should be measured, and, as a result, a multitude of indicators have been proposed (Horn 1985). None of those indicators is able to perfectly capture the complexity and intangibility of some aspects of competitiveness (Latruffe 2010), but a consensus has emerged that places productivity at the centre of any sector-level analysis. For instance, Paul Krugman considers that competitiveness is just "a funny way of saying 'productivity'" (Aiginger 2006, summarizing Krugman 1994) and the UK Department for Food \& Rural Affairs (DEFRA) concluded its review of competitiveness indicators for the food chain industries by stating that: "At root, therefore, competitiveness should be viewed as being about economic efficiency or productivity" (DEFRA 2002).

With this in mind, the core of the paper seeks to measure and compare the productivity of milk farms in the study region, but this information is complemented by detailed information collected in the eight countries through interviews. This permits the development of a rich narrative explaining how the competitiveness positions of dairy farmers have changed in the EU countries of Northern Europe, and what changes are likely to take place in the near to medium future in the Baltic Sea region. 


\section{General Approach and Methodology}

The productivity of a firm or sector is simply defined as the ratio of outputs (e.g., yoghurt, butter) to inputs (e.g., labour, milk) (Coelli et al. 1998). The value of the index is uninformative by itself, but its rate of change measures the growth in output that is not explained by the growth in inputs and therefore directly captures how the efficiency of the production process fluctuates over time. Further, productivity indicators can be compared at a given point in time across countries to capture the relative competiveness of those countries. We consider that both types of comparisons are highly relevant to this study and therefore pursue the measure of productivity growth and productivity levels of milk farms in the countries of the Baltic Sea region.

If the production process involved a single input and a single output, calculating productivity levels would be straightforward, but this is unfortunately never the case in reality, where firms (or farms) combine multiple production factors in order to manufacture a whole range of products. Hence, the problem of measuring productivity becomes one of aggregating inputs and outputs into appropriate indices. This can be achieved by application of various methods that differ in terms of accuracy, ease of implementation and data requirements, but two types of measures can be broadly distinguished:

- Partial productivity measures, which simplify the problem of aggregating inputs and/or output by focusing on only one of each (e.g., milk for outputs, labour, dairy cows or land for inputs). The main advantage is the ease of calculation and interpretation, but it comes at the cost of accuracy. For instance, a high level of labour productivity can reflect high efficiency resulting from the use of a superior technology, but it can also be due to the inefficient substitution of capital for labour. In a similar vein, at the level of a farm, high milk yields can be sub-optimal if they are achieved through an inefficient use of costly feeds. It is therefore clear that partial productivity measures can provide a misleading indication of overall productivity when considered in isolation.

- Total Factor Productivity (TFP) measures, which integrate all inputs and all outputs in the calculation.

Although the academic literature favours the analysis of TFP, we believe that investigating partial productivity indicators in conjunction brings additional insights regarding the technical performance of farms and the potential bias of technical change. Further, comparison of TFP levels across countries, although not impossible, raises considerable methodological challenges (Barath and Ferto 2014), so that the analysis of the cross-country performance of dairy sectors at a given time is much more easily pursued by relying on partial productivity indicators.

Partial productivity measures are almost self-explanatory but our selection of specific indicators is guided by the literature on technical change and development in agriculture of Hayami and Ruttan (1991). Specifically, labour productivity $(\mathrm{Y} / \mathrm{L})$ is partitioned into output per dairy cow $(\mathrm{Y} / \mathrm{C})$ and the number of dairy cows per worker $(\mathrm{C} / \mathrm{L})$ according to the relationship: $\mathrm{Y} / \mathrm{L}=\mathrm{Y} / \mathrm{C}^{*} \mathrm{C} / \mathrm{L}$. The advantage of this decomposition lies in the sources of growth in each of the partial productivity indicators: an increase in output per dairy cow (i.e. milk yield) reflects mainly biological innovations, such as genetic improvements or the amelioration of feed composition. On the other hand, the number of dairy cows per worker changes mainly with mechanical innovations, such as the labour requirement of milking machines or automation of other production processes such as feeding, cleaning, maintenance.

A variety of methods are available for the measurement of TFP growth. When prices of all outputs and all inputs are available, that information is easily combined with quantity data in order to produce traditional indices, such as Laspeyres, Paasche, Fisher, and Tornqvist indices. Coelli et al. (1998) demonstrate that the Tornqvist index has superior economic properties and is therefore used in this analysis. Formally, it is constructed from an output index and an input index:

$$
\begin{aligned}
& \ln \left(\frac{\text { Input }_{t}}{\text { Input }_{t-1}}\right)=\sum_{i=1}^{n} 1 / 2\left(\alpha_{i, t}+\alpha_{i, t-1}\right) \ln \left(\frac{x_{i, t}}{x_{i, t-1}}\right) \\
& \alpha_{i, t}=\frac{w_{i, t} x_{i, t}}{\sum_{j=1}^{n} w_{j, t} x_{j, t}}
\end{aligned}
$$




$$
\begin{aligned}
& \ln \left(\frac{\text { output }_{t}}{\text { output }_{t-1}}\right)=\sum_{k=1}^{m} 1 / 2\left(\beta_{i, t}+\beta_{i, t-1}\right) \ln \left(\frac{y_{i, t}}{y_{i, t-1}}\right) \\
& \beta_{i, t}=\frac{p_{k, t} y_{k, t}}{\sum_{l=1}^{m} p_{l, t} y_{l, t}}
\end{aligned}
$$

where $x_{i, t}$ denotes the quantity of input $i$ used in period $t ; w_{i, t}$ is the price of that input; $y_{k, t}$ denotes the quantity of output $k$ produced in period $t$ and sold at a price $p_{k, t}$. In spite of the cumbersome notations, these expressions have a simple interpretation once it is recognized that, for any variable $v, \ln \left(v_{t} / v_{t-1}\right)$ is the growth rate of $v$ between $t-1$ and $t$. The total growth rate of inputs $\ln \left(\right.$ Input $/$ /Input $\left.t_{t-1}\right)$ is therefore a weighted average of growth rates of individual inputs $\ln \left(x_{i, t} / x_{i, t-1}\right)$, with the weights equal to the average cost shares of the inputs. Similarly, the total growth rate of outputs $\ln \left(\right.$ Output $_{t} /$ Output $\left.t_{t-1}\right)$ is a weighted average of growth rates of individual outputs $\ln \left(y_{k, t} / y_{k, t 1}\right)$, with the weights equal to the average revenue shares of each output $j$. TFP growth, defined as the growth in output not explained by growth in inputs, is therefore calculated as the difference between the two previous expressions:

$$
\ln \left(\frac{T F P_{t}}{T_{F P_{t-1}}}\right)=\ln \left(\frac{\text { output }_{t}}{\text { Output }_{t-1}}\right)-\ln \left(\frac{\text { Input }_{t}}{\text { Input }_{t-1}}\right)
$$

Recognising the impossibility of capturing the complexity and multidimensionality of competitiveness, and in a search for explanations of the differences in growth rates and levels of productivity across countries, we complemented the quantitative analysis by carrying out interviews (more than 100 in total) in each country with dairy farms and key stakeholders in associations, industry, government and research. This allowed us to document the structural characteristics and changes of the dairy supply chains in the studied countries, and we draw on that information in the interpretation of the productivity analysis (see the Appendix for the number visited organisations by country).

\section{Data and construction of variables}

The analysis of productivity of dairy farms relies on the aggregate data provided by the European Commission's Public Database of the Farm Accountancy Data Network (FADN, http://ec.europa.eu/agriculture/rica/index.cfm). The FADN is a sample survey of a field of observations composed of commercial farms (i.e., exceeding a size threshold) and excluding small, subsistence farms. This characteristic makes it possible to compare agriculture in countries at different stages of economic development. For the eight countries of the Baltic Sea region included in the study, the information extracted from the database pertains to the TF14 grouping entitled "Specialist milk farm" (i.e. group 41 for the old classification based on gross margins before year 2004, and group 45 for the new classification based on standard output thereafter). The study covers the period from 1995 to 2010 . The database, being run by EU institutions, contains information from member states and this means that for the relatively new entrants, the data is only available from the year of EU accession (2004 for the three Baltic States and Poland). Throughout this article, the eight countries are classified into two broad groups: Germany, Denmark, Sweden and Finland are referred to as the old EU member states, while the other four countries (Estonia, Latvia, Lithuania and Poland), which joined the EU in 2004, are referred to as new members.

Detailed information is available on the main aspects of the production process. Output values at current prices are recorded for milk, crop productions and beef/veal, which makes it possible to calculate the revenue shares $\beta$ in equation (2). The corresponding quantity indices entering the definition of the output index (2) for crop productions and beef/veal are then calculated by deflating the current value figures, using the deflators in the EUROSTAT database. For milk, information is available on the number of dairy cows as well as milk yield, and it is therefore possible to infer a physical quantity of milk produced. 
Input values are recorded for the main variable production factors, namely fertilisers, commercial feeds, pesticides, energy and seeds. The issue of family labour, which represents typically an important factor of production that is not directly paid, is addressed as follows. An average wage rate is calculated as the ratio of the wage bill to the quantity of paid labour, which is then applied to the input of family labour in order to infer the total cost of labour (family as well as hired).

Capital inputs are more difficult to take into account because what should be entered the productivity calculations are the flow variables, i.e., the productive services and associated costs provided by all the capital goods, although the database only records capital stocks for four classes of assets: land, buildings, machinery and livestock. Hence, for each asset class, we build the cost of capital as the sum of depreciation costs and opportunity cost of the investments. The first component is calculated assuming linear depreciation over 20 years for buildings, seven years for machinery, and five years for livestock, while land is assumed not to depreciate. The opportunity cost of capital is calculated as the interests that would have been earned by a near risk-free investment of the same value. The corresponding interest rate is approximated by the yield on long-run government bonds, as given by the European Central Bank (ECB) database (http://sdw.ecb.europa.eu/browse.do?node=bbn3146). By adding the depreciation and opportunity costs of the four classes of capital goods, one obtains the total cost of capital which is then used to calculate the cost share in the total input index (1). The growth in the quantity of capital in (1) is then calculated by using deflated values of buildings, machinery and livestock, while the physical quantity of land (i.e., surface area) is used for that asset.

\section{Results}

\section{Cross-country comparison of partial productivity levels and growth rates}

Labour productivity is perhaps the most widely used indicator to compare the competiveness of whole economies and sectors-seefor instance O'Mahonyand Timmer (2009) for a recent example-and offers a natural starting point for our analysis. Table 1 indicates that the performance of dairy farms in terms of labour productivity varies tremendously across countries.

Table 1. Partial productivity of dairy farms

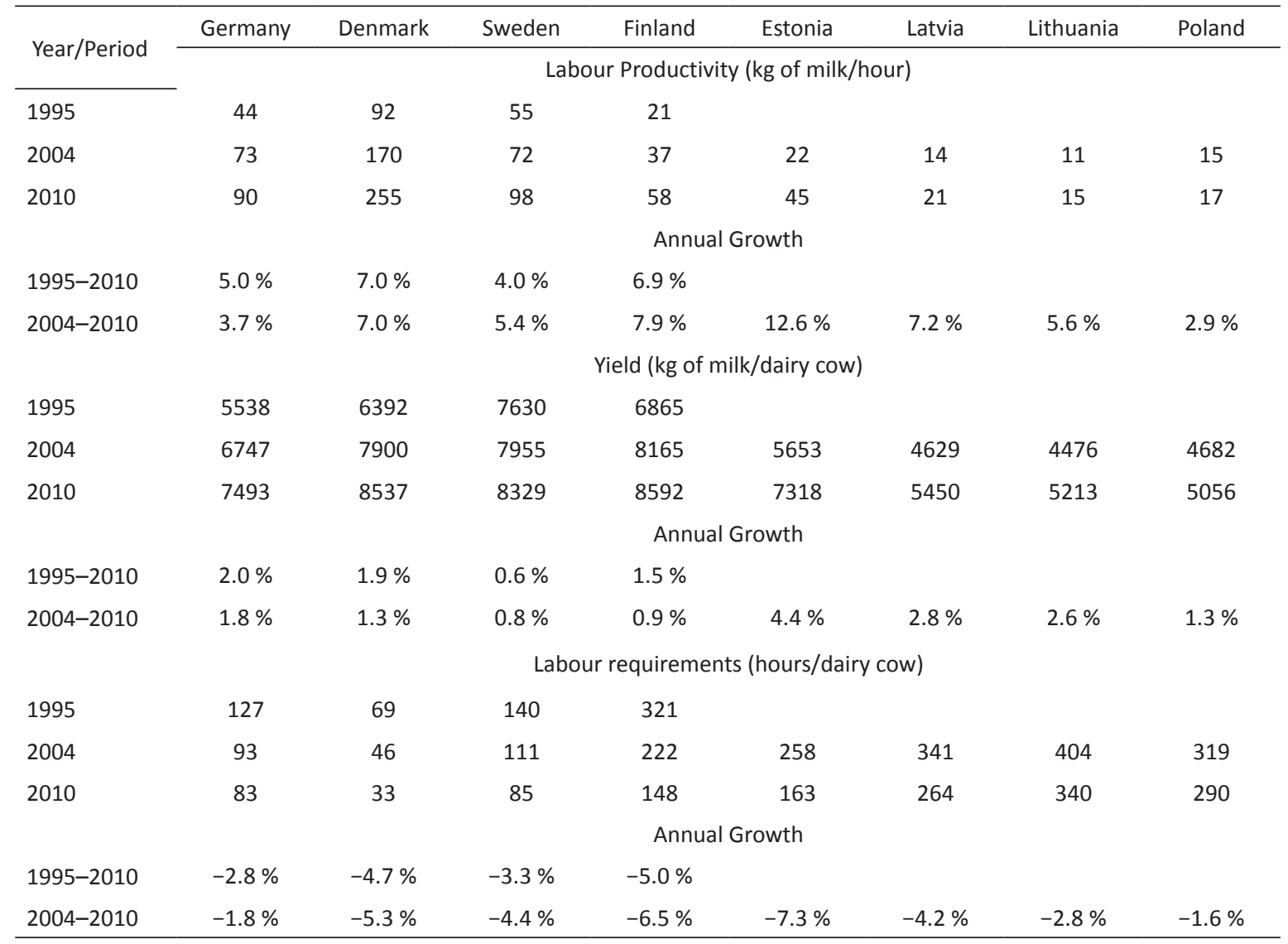

Source of data: FADN 
In 2010, for instance, one hour of labour on a dairy farm produced on average $255 \mathrm{~kg}$ of milk in Denmark but only $58 \mathrm{~kg}$ in Finland and $15 \mathrm{~kg}$ in Latvia - a variation of a factor 17. On the basis of that indicator, Finnish dairy farms are not very competitive, lagging behind those in Denmark, Sweden and Germany. The new entrants have much lower levels of labour productivity than Finland, although Estonian farms outperform Latvian, Lithuanian, and Polish farms by a large margin.

Looking at changes over time, labour productivity has been increasing rapidly in all countries. The speed of growth over the 1995-2010 period in the four older EU member states varies from 3.7\% for Germany to 7.9\% for Finland. However, those differences in growth rates for this group of countries have not been sufficient to significantly change competitive positions: Denmark is the clear leader throughout the period, Sweden and Germany have rather similar levels of productivity, while Finland lags behind.

Turning to the situation of the new entrants, Estonia stands out from its large growth rate of labour productivity (+13\% annually), which is significantly larger than the Finnish rate over the 2004-2010 period, and the labour productivity gap between Finnish and Estonian farms has therefore decreased. By contrast, there is no evidence of the other three new entrants catching up in terms of labour productivity, with Polish farms displaying particularly low rates of growth of that indicator.

As discussed in the methodology section, labour productivity has two components, milk yields and labour requirements per dairy cow, which we now investigate. Figure 1 shows that there are important differences in yields across countries, but that three groups of countries can be defined at the end of the period:

- The yield leaders include Finland, Denmark and Sweden. For those countries, a dairy cow produces on average roughly $8500 \mathrm{~kg}$ of milk.

- Germany and Estonia form an intermediate group of countries, with yields around $7500 \mathrm{~kg}$ per dairy cow.

- The "laggard" countries - Latvia, Lithuania and Poland - display yields around 5000kg per dairy cow.

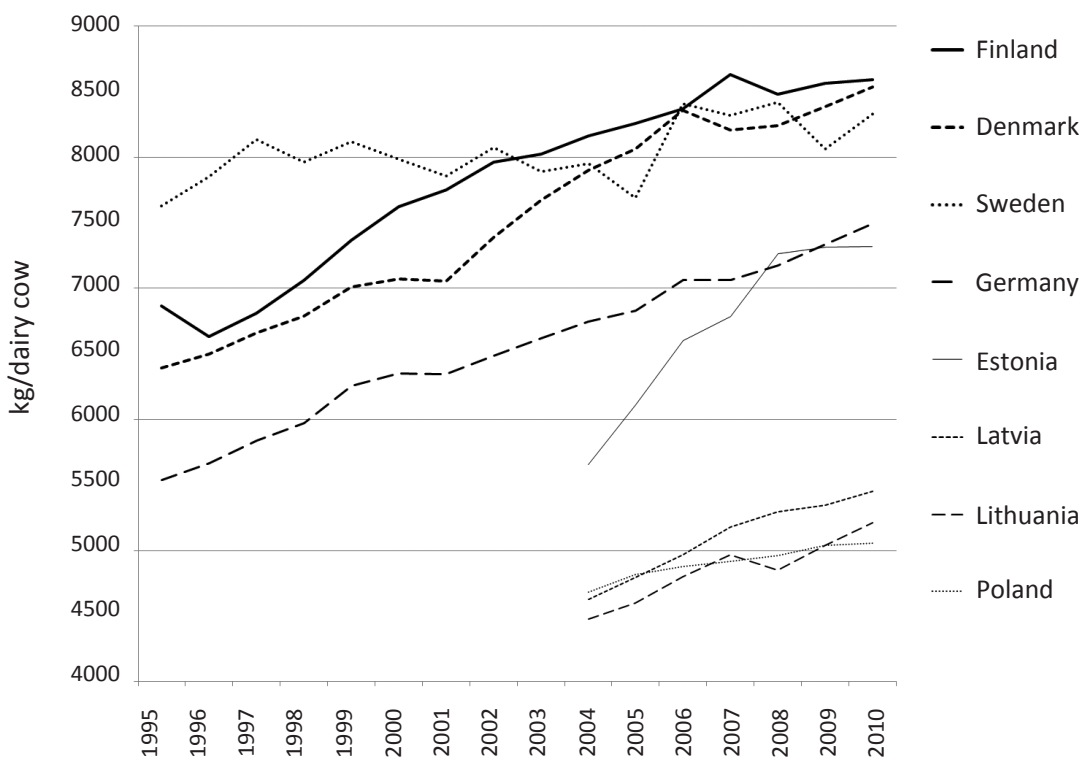

Fig. 1. Evolution of milk yields Source of data: FADN

Milk yields are clearly increasing over time (Fig. 1 and Table 1 ) but the speed of the growth is limited, usually under $2 \%$ annually. The exception is Estonia, which managed to close its yield gap with Germany after joining the EU. From 1995 to 2010, the Finnish, Danish, and Swedish yields converged and the calculations suggest that growth in yields beyond $8000 \mathrm{~kg}$ is becoming increasingly difficult. In particular, one notes that yields have not increased much among the yield leaders over the last four years of the study, and Table 1 also shows that for all four old EU member states but Sweden, growth in yields over the period 2004-2010 was significantly less than over the period 1995-2010. 
Hence, one can postulate that the biological innovations supporting yield growth, such as better genetics and improved feeding, are reaching a phase of marginal decreasing returns. This means in particular that improving performance on, for instance, Finnish dairy farms through yield increases is becoming more and more difficult. On the other hand, as exemplified by the Estonian experience, Latvia, Lithuania and Poland probably have the potential to raise their productivity considerably through the achievement of higher yields, although this potential has, so far, not been fully exploited. We refer readers interested in the development of the Polish and Latvian dairy sectors to the studies of Dries et al. (2011) as well as Krievina (2012).

Labour productivity is also dependent on per unit labour requirements, measured by the number of hours of labour per dairy cow in Figure 2 and Table 1.

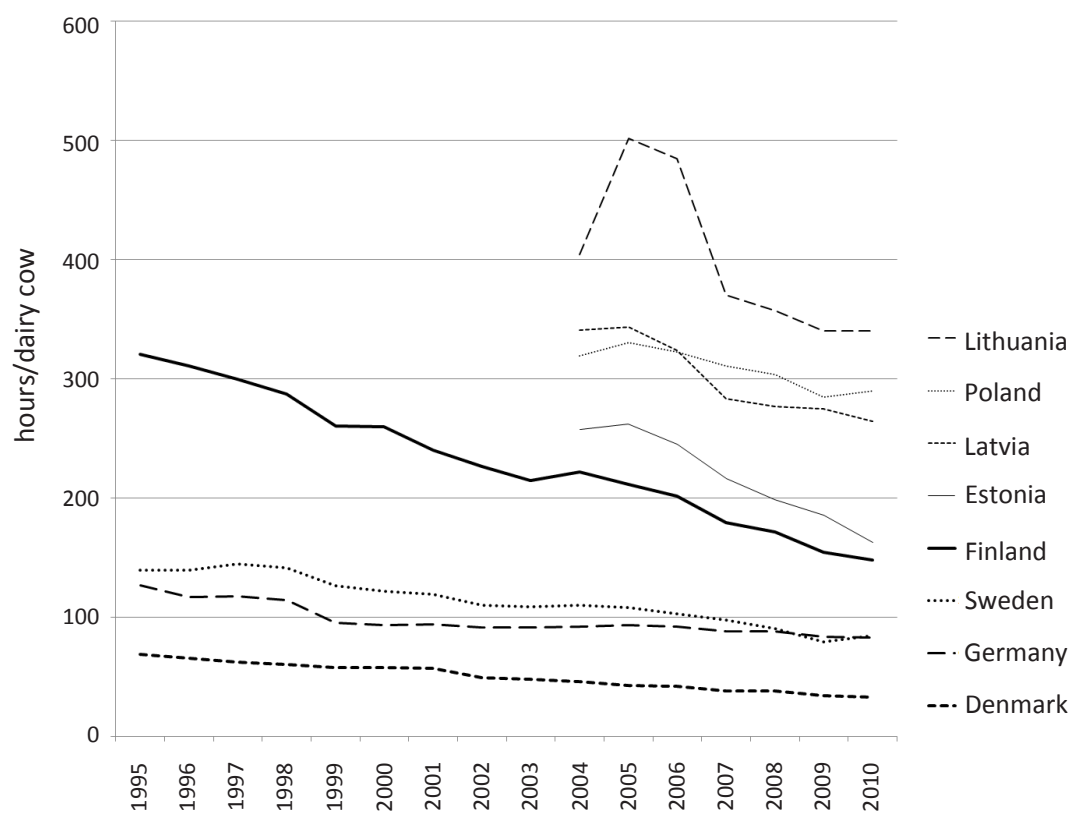

Fig. 2. Evolution of labour requirements per dairy cow Source of data: FADN

The results indicate that this component is much more important than yields in explaining differences in levels and growth of labour productivity. For instance, in year 2010 a Lithuanian dairy cow required on average ten times more labour than a Danish cow, and it is clearly in that dimension that, within the group of older EU members, Finnish farms are performing poorly compared to their competitors, with a requirement of 148 hours per dairy cow in 2010. This is more than four times the corresponding figure for Danish cows, and nearly twice the labour requirements for German and Swedish cows. It is also worth noting that Estonia is also catching up with Finland in that dimension, which indicates that the distinction between older and newer member states is becoming less relevant with the passing of time.

\section{Partial productivity and farm structure}

Visits of farms in the eight countries as well as discussions with key informants pointed to the importance of differences in farm structure to explain the comparative performance of dairy farms in the Baltic Sea region. This idea is investigated further by drawing a parallel between labour productivity and farm structure, measured by the average number of dairy cows per farm, in Figures 3 and 4.

Before interpreting the figures, we must acknowledge that the high proportion of subsistence farms in the New Member States distorts the cross-country comparison of farm structures somewhat. To illustrate, in 2010, as much as $27 \%$ of the milk produced in Poland was not delivered to the processing sector. In Estonia, Latvia and Lithuania, the corresponding shares were $10 \%, 25 \%$ and $26 \%$ in the same year (Eurostat). If we assume that the holdings with 1-2 cows tend to use their milk and not deliver it for processing, and consequently exclude those farms from the calculations, average farm size jumps from 6 cows/farm to 13 in Poland, from 6 to 15 in Latvia and from 4 to 12 in Lithuania. 
The biggest difference occurs in the case of Estonia, where excluding the smallest holdings inflates average farm size from 27 cows/farm to 66, a level that exceeds that of Germany. At the same time, since subsistence farming is practically non-existent in the Old Member States, a similar exclusion of the smallest holdings in Finland, Germany, Sweden and Denmark would not change average farm size in those countries.

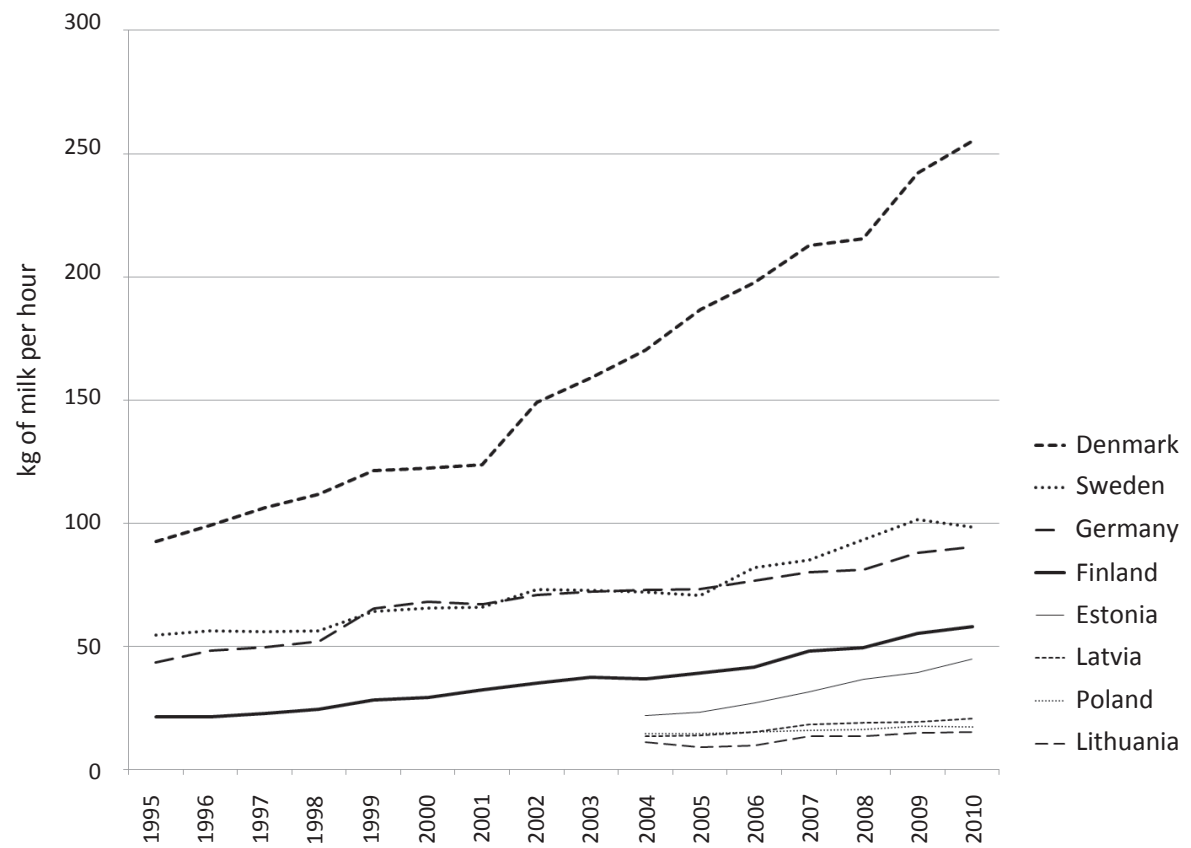

Fig. 3. Evolution of labour productivity Source of data: FADN

The similarities in terms of growth rates and levels of the two variables are striking and highlight the importance of the initial structure of dairy farms (i.e., in 1995 for the older EU members, and 2004 for the newer ones) in determining the evolution of labour productivity (Figs. 3 and 4). On average, Denmark's dairy farms had 44 cows in 1995, as compared to 27, 25 and 12 for Sweden, Germany and Finland respectively. Farm size increased in Denmark at a fairly moderate pace until 2000 , followed by an acceleration in the speed of structural change, and labour productivity shows the same pattern of evolution.

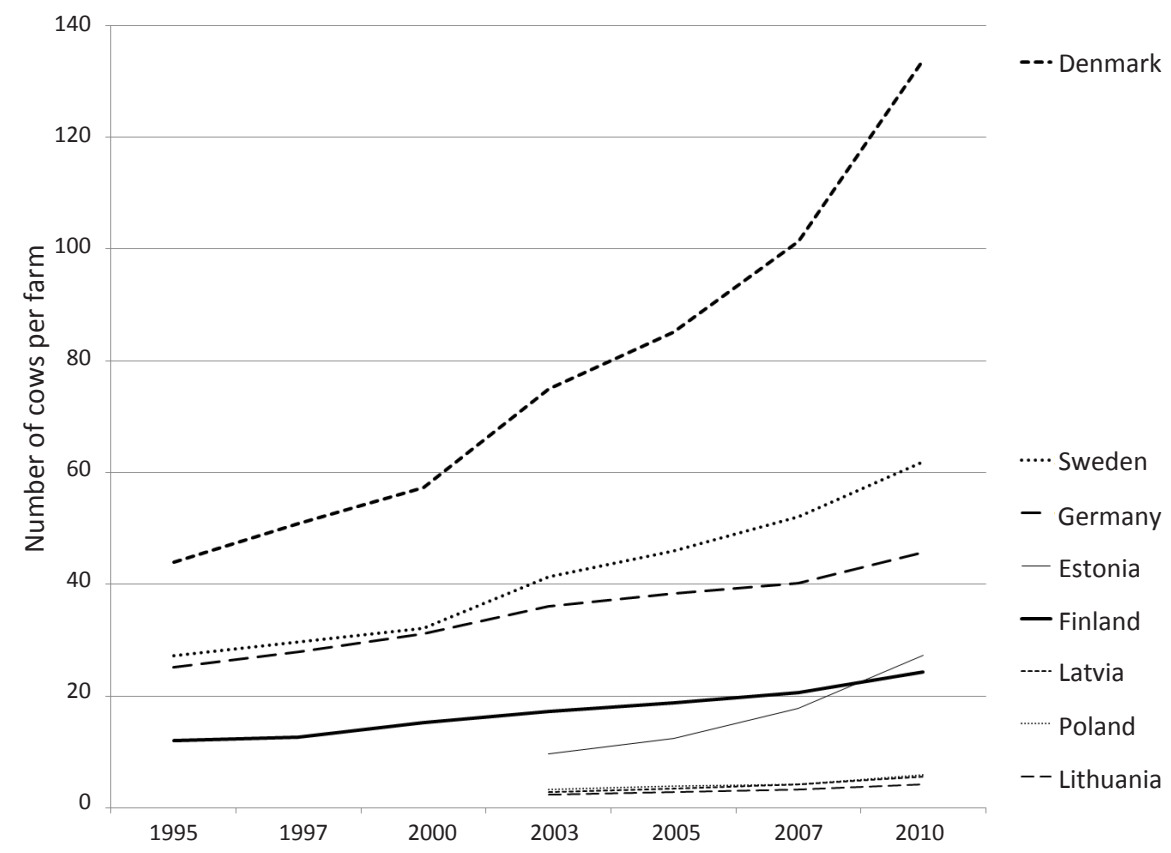

Fig. 4. Evolution of farm structure Source of data: EUROSTAT 
The association between average farm size and labour productivity is also observed for Sweden and Germany. Sweden set off with a slightly higher average farm size than Germany in 1995, but structural change was comparable in the two countries until 2000, when concentration of dairy farms became a bit faster in Sweden than Germany. Over this latter period, labour productivity growth was also slightly larger in Sweden than Germany.

Compared to their counterparts in Germany, Sweden and Denmark, Finland's milk farms started with a much smaller average dairy herd but structural change proceeded at a steady pace throughout the study period. As a result, the structure of Finnish dairy farms was, in 2010, roughly comparable to that of Swedish farms in 1995, and the similar observation that Finland is lagging 15 years behind Sweden can be made on the basis of the labour productivity indicator.

In the case of new EU member states, average farm size and the speed of structural change also explain crosscountry differences in labour productivity. Prior to EU accession in 2004, dairy farms in Estonia were, on average, three times larger than farms in Latvia, Poland and Lithuania. Subsequently, the pace of structural change was also much higher in Estonia than in any of the other three countries, and a similar development was observed about labour productivity. The reasons of the fast structural transformation of the Estonian dairy sector are discussed further in Viira et al. (2009). The rapid concentration of farms in Estonia has accompanied the catching up of labour productivity towards levels observed in the old member states, while the slow pace of structural change in the other three new entrants seems to explain the widening of the productivity gap separating them from the other countries of the Baltic Sea region

While the association of labour productivity to average farm size appears to have generality, some exceptions are worth exploring. In year 2010, for instance, Estonian milk farms had, on average, 27 dairy cows, which compares favourably to Finland's 24 cows per milk farm. In fact, with correcting for the subsistence farming, the average farm would have as many as 66 cows in Estonia in 2010. In terms of labour productivity, however, Estonia is still lagging behind Finland, although its catching up is evident from Figure 3. This discrepancy can be explained by substantially different wage levels in the old and new member states. Salary differences between the two groups of countries may be three to fivefold. Hence, the availability of relatively cheap labour limits the incentive of large and expanding Estonian dairy farms to reduce labour input. On the other side of the coin, lower salaries create a severe challenge for Estonian dairy farms to find professional skilled labour force, as low wages often cause a lack of motivation and non-efficient work practices.

Changes in the structure of milk farms have direct impacts on both components of labour productivity and this is what ultimately explains the peculiar similarities between the evolution of average farm size and labour productivity. As a general rule larger family farms tend to pay more attention to milk output per cow than smaller ones. This especially applies in the new member states where tiny farms with few cows coexist with production units with 10 to 60 cows and a stronger market orientation.

The relatively quick catch up of Estonian milk farms in terms of labour productivity to levels observed in old member states is also attributable to the specific characteristics of the Estonian milk sector and its concentration. Estonia has a few thousands of "small" herds with less than 10 cows, but over three fourth of the dairy cows are held in large herds of over 100 heads. Most of the large herds feature extremely high labour productivity by international standards. Concentration is quick because of the rapid exit of small farms, which results in the increasing weight of large farms in the average productivity measure. Consequently, labour productivity also improves very fast.

Average farm size also affects labour requirements per cow through its impact on the organisation and utilisation of work on dairy farms. Dairy farms with up to 60-100 cows can, in principle, be operated by relying solely on labour from the owner-farmer and his/her close family. The operation of dairy farms necessitate a lot of fixed work which is not strongly related to the number of animals, such as the general management of the farm, maintenance of fixed assets and servicing of equipment. Even feeding and milking involve phases (e.g., cleaning of the milking equipment, transport of feeds to the farm), which require the same amount of work for herds of 20 or 50 cows. The bigger the herd, the less work is needed per unit of output, because the marginal use of labour for an additional milk cow is minimal.

For farms with more than 80 cows, technological developments permitting the substitution of capital for labour have driven labour productivity to entirely new levels. One milking robot usually serves a 70-head herd, but a single robot is rarely installed on expanding farms. Hence, milking robots have created constraints on farm expansion, which means that growth usually proceeds in discrete steps corresponding to 70, 140, 210 etc dairy cows. 
If robots are to be used, most usually two or several of them are installed in expanding farms, which radically decreases the amount of labour required per cow. Similarly feeding, cleaning and manure removal have been automated to a great extent in farms of 150 cows or more. Those technological aspects explain particularly well the sharp rise in labour productivity in Denmark, where average farm size jumped from 50 to over 130 cows in just about ten years.

Expanding farms achieve higher labour productivity in all countries due to higher use of capital and better organisation of work. The technology installed in the expanding farms of Germany, Sweden and Finland is the same as in Denmark. Nevertheless, it is primarily the intensity of new investments and the number of expanding farms that determine the pace of farm restructuring and, concurrently, the speed of labour productivity growth.

\section{TFP Growth across countries}

Concerning the TFP growth analysis, we start with a growth accounting exercise focusing on the old EU member states. Figure 5 demonstrates graphically that in all four countries productivity of dairy farms has increased significantly from 1995 to 2010, with the total increase ranging from 43\% for Germany and Sweden to almost 60\% for Finland. Although, overall, Finland displays the largest rise in TFP, differences among the four countries are small and vary from year to year, so that not too much should be read from the final ranking. In particular, we note that the increase in productivity in Finland has been very comparable to that in Denmark, and that in the last two years of the study period (from 2008 to 2010) Finland moved from third to first in terms of overall increase in TFP. Thus, TFP growth has been roughly comparable in the four countries considered here. Although dairy farms in Sweden and Denmark have experienced a sharp decrease in TFP in year 2010, the analysis suggests that this is only a temporary phenomenon. However, only the addition of more recent data will permit to check the validity of that conjecture.

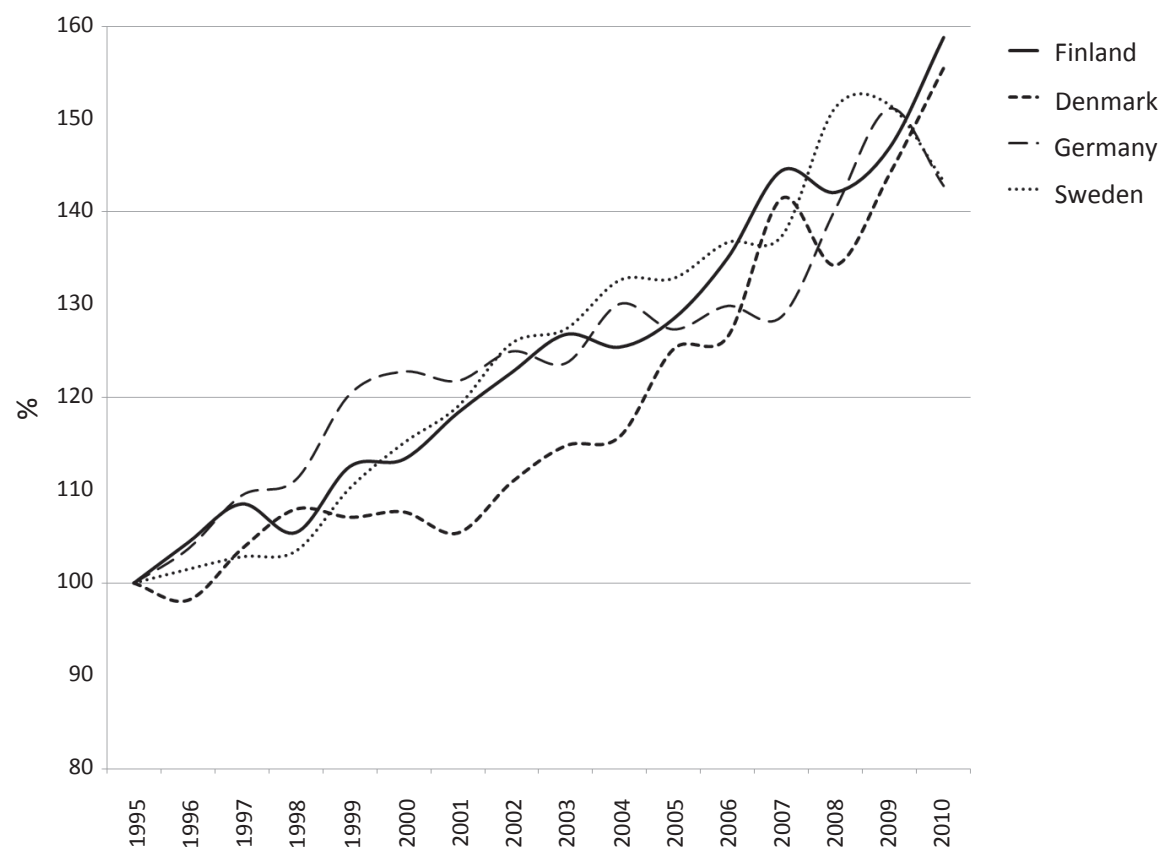

Fig. 5. TFP growth in old member states Source of data: FADN, EUROSTAT and ECB

Table 2 provides the full growth accounting results, from which it is clear that productivity growth in the four countries, although of a similar magnitude, has been achieved through different channels. Output per farm has expanded in all four countries, but the annual growth rate for Denmark (10.4\%) stands out as particularly high (the corresponding rate for Finland is only 6.4\%). We also note that growth in milk production in Finland accounts for a much larger share of total output growth than in the other countries ( $87 \%$ versus $64 \%$ for Sweden for instance). Thus, dairy farms in Finland are becoming relatively more specialised than those in the other three countries. 
Table 2. Partial productivity of dairy farms

\begin{tabular}{|c|c|c|c|c|c|c|c|c|c|c|}
\hline \multirow[t]{2}{*}{ Country } & \multicolumn{4}{|c|}{ Annual output growth (\%) } & \multicolumn{5}{|c|}{ Annual Input growth (\%) } & \multirow{2}{*}{ TFP growth (\%) } \\
\hline & TOTAL & Milk & Crop & Livestock & TOTAL & Feeds & Capital & Labour & Other & \\
\hline & \multicolumn{10}{|c|}{ 1995-2010 } \\
\hline Germany & 5.6 & 4.4 & 0.8 & 0.4 & 3.1 & 1.0 & 1.1 & 0.2 & 0.7 & 2.4 \\
\hline Sweden & 7.4 & 4.8 & 1.9 & 0.6 & 4.9 & 2.2 & 1.3 & 0.9 & 0.4 & 2.4 \\
\hline Denmark & 10.4 & 7.3 & 2.4 & 0.5 & 7.2 & 2.9 & 3.1 & 0.5 & 0.4 & 3.0 \\
\hline \multirow[t]{2}{*}{ Finland } & 6.4 & 5.6 & 0.5 & 0.3 & 3.2 & 1.1 & 1.8 & -0.1 & 0.3 & 3.1 \\
\hline & \multicolumn{10}{|c|}{ 2004-2010 } \\
\hline Germany & 5.7 & 4.0 & 1.2 & 0.4 & 4.0 & 1.6 & 0.8 & 0.5 & 1.1 & 1.6 \\
\hline Denmark & 13.7 & 7.1 & 5.5 & 0.6 & 7.9 & 5.1 & 1.7 & 0.5 & 0.5 & 5.8 \\
\hline Sweden & 4.5 & 4.4 & 0.0 & 0.1 & 3.2 & 1.4 & 1.1 & 0.5 & 0.2 & 1.3 \\
\hline Finland & 6.7 & 5.9 & 0.6 & 0.1 & 2.6 & 1.1 & 1.3 & -0.4 & 0.5 & 4.1 \\
\hline Estonia & 6.1 & 4.5 & 1.2 & 0.4 & 3.6 & 2.7 & 1.6 & -1.1 & 0.4 & 2.5 \\
\hline Latvia & 0.8 & 2.6 & -1.4 & -0.4 & -1.0 & 0.1 & 0.3 & -0.8 & -0.6 & 1.8 \\
\hline Lithuania & 7.3 & 4.1 & 1.7 & 1.4 & 7.7 & 1.0 & 5.9 & 0.5 & 0.1 & -0.3 \\
\hline Poland & 3.8 & 2.5 & 0.3 & 1.0 & 3.5 & 1.1 & 1.8 & 0.2 & 0.4 & 0.3 \\
\hline
\end{tabular}

Source of data: FADN

The input side section of Table 2 reveals that a large share of the growth in output has been achieved by increasing the quantities of production factors, at an annual rate varying from 3.1\% for Germany to 7.2\% for Denmark. The countries with the highest output growth rates are also those with the highest input growth rates and there is therefore no "miracle growth". In all countries, other inputs are substituted for labour, but the relative contributions of feeds and capital to input growth vary. For instance, the contribution of capital investments to input growth is much larger in Finland than in Sweden, where the increase in feeds has played a quantitatively larger role. Denmark stands out by the importance of capital to input growth, which reflects the high level of investment by Danish dairy farms over the last two decades.

We now present the results of the growth accounting exercise for the four new entrants over the period 20042010. The evolution of the TFP index presented graphically in Figure 6, which indicates that the situation for those countries is not very stable, with important year-to-year variations in the productivity of dairy farms. The shock of entry into the EU was followed by a decline in productivity, which stopped between 2006 and 2008, followed by some productivity growth, but TFP actually decreased again in three countries in year 2010. The frustratingly short time series make it difficult to infer long-term trends.

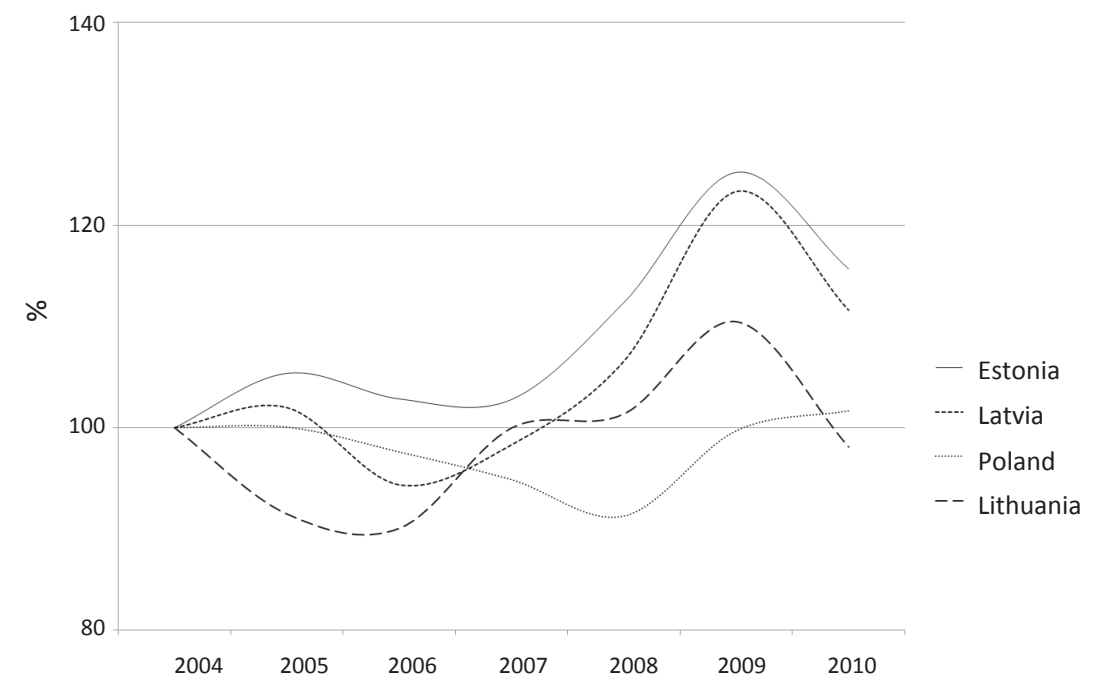

Fig. 6.TFP growth in new member states Source of data: FADN, EUROSTAT and ECB 
Table 2 also presents the full growth accounting results for all eight countries from 2004 to 2010. Over that period, Finland had the second highest TFP growth rate, with farm productivity growing faster only in Denmark. These TFP growth rates were significantly larger than in the four newer EU members, and there is therefore no evidence that those countries are catching up in terms of TFP, as could have been thought at least for Estonia by focusing on partial productivity indicators. It is also worth noting that in some newer member states such as Lithuania and, to a lesser extent, Poland, the relative slow TFP growth can be attributed to fast capital input growth. This can be explained by investments supported by EU accession funds and the need to upgrade food safety management systems so as to meet EU standards. Following those one-off upgrades, investments may deliver more rapid TFP growth in the future.

\section{Conclusions}

Dairy farms in the new EU members of the Baltic Sea region have lower levels of labour productivity than farms in the old EU member states, but Estonian farms outperform Latvian, Lithuanian, and Polish farms by a large margin on the basis of that indicator. Indeed, productivity of labour on Estonian farms is now only $20 \%$ lower than productivity of labour on Finnish farms. Cross-country differences in farm labour productivity are driven primarily by differences in labour requirements per cow, while differences in milk yields account for a much smaller share of the difference. This suggests that the key to high labour productivity in dairy is the farm structure and the adoption of mechanical innovations, while differences in adoption of biological innovations (e.g., genetic improvement, feeds)are relatively less important. This is reinforced by the finding that yield growth has been relatively slow in the old EU members and appears to become increasingly difficult.

Concerning the old member states, Finland has matched Denmark and outperformed Germany and Sweden in terms of both labour productivity growth and TFP growth over the entire 1995-2010 period. However, it is more difficult to compare performances in terms of TFP levels because the TFP index is normalized in the first year of the study for all countries (i.e., although the index is arbitrarily set to 100 , it does not mean that productivity levels were equal across countries at the beginning of the period). Indeed, Sipiläinen et al. (2008) showed that, in year 2003, Finnish dairy farms lagged both their Swedish and Danish counterparts by a significant margin. Eventually differences in rates of growth were small and the competitive positions of those four countries have consequently not changed dramatically over the 15 years of the study period. Hence, farm-level milk production in those countries appears caught on a technological treadmill, which delivers high rates of TFP growth for all but no change in relative competitiveness.

TFP growth has been faster in the old member states, particularly in the Finnish and Danish farms, than on farms of the new EU members over the 2004-2010 period. Hence, the high rates of growth in labour productivity calculated for Estonian and, to a lesser extent, Latvian farms, have been driven more by substitutions of other inputs for labour rather than real efficiency gains. Productivity of Polish and Lithuanian dairy farms has yet to really take off. Hence, at farm level, TFP in the new EU countries is not converging to its level in the old EU members. Transferring technologies from the productivity leaders to the productivity laggards appears difficult in the primary sector, most likely due to the relatively small size of firms and importance of country-specific agro-ecological conditions.

Elsewhere Jansik et al. (2014) found an opposite result based on estimates of TFP growth rates in dairy processing in countries of the Baltic Sea region. That publication, which also gives a more complete comparison of farm structure in the eight countries and presents detailed country-level reviews of dairy sectors, reports a growth accounting exercise establishing that cross-country convergence in TFP occurred in dairy processing, i.e. the new EU members (primarily Poland and Lithuania) have been catching up with the old EU members. These findings, combined to ours, suggest that the transfer of technologies and management techniques is easier in the industrial sector where company size and industrial concentration is considerably larger than in the farm sector.

Besides productivity development, the competitiveness of the dairy supply chain is determined by many factors, including the farm and industry structure within the chain, the transactions among actors in the chain, growth on the domestic and export markets as well as innovation. One of the key factors to determine future competitiveness of a country's dairy chain is the growth potential of milk production. In the past milk production has increased in most of the countries considered here except Sweden and Finland. Sufficient raw material supply is a basic condition for dairy processors' growth, which will ultimately contribute to the competitiveness of national dairy supply chains. 
Finally, the analysis presented here allows us to anticipate some changes in the competitiveness of primary milk production in the countries of the Baltic Sea region in the medium to long term. Changes in farm structure result from steady, long-term forces and are, therefore, relatively easy to forecast. This makes it possible to anticipate labour productivity growth, given its association to the speed of structural change. On that basis, one can expect that, in terms of labour productivity, Estonian dairy farms will soon overtake Finnish dairy farms and perform as well as German and Swedish farms in 10 to 15 years. On the other hand, the productivity of labour on Polish, Latvian and Lithuanian milk farm will continue to rise very slowly, so that the productivity gap to the leader countries will most probably widen in the next decade or two due to the heavy weight of small farms and their relatively slow exit rates.

Lastly, we must acknowledge some limitations of our analysis, which give directions for future research. One issue relates to the fact that we are only comparing TFP growth rates rather than TFP levels across countries. While we believe that the growth accounting results combined to the analysis of partial productivity differences generates important insights about the relative competiveness of the national milk sectors within the Baltic Sea region, studying differences in TFP levels of milk production would be interesting. At that level, we may seek to apply the conceptual framework developed by O'Donnel (2012) and extend the empirical contribution of Barath and Fertő (2014) to compare TFP levels within the EU for different agricultural sub-sectors.

\section{References}

Aiginger, K. 2006. Revisiting an evasive concept: introduction to the special issue on competitiveness. Journal of Industrial Competition \& Trade 6: 63-66.

Barath, L., \& Fertő, I. 2014. Agricultural Productivity in the EU: A TFP Comparison between the Old (EU-15) and New (EU-10) EU Member States. 142nd EAAE Seminar, Growing Success? Agriculture and rural development in an enlarged EU, Budapest, Hungary. $18 \mathrm{p}$.

Coelli, T., Rao, D.S.P. \& Battese, G.E. 1998. An introduction to efficiency and productivity analysis. Boston: Kluwer Academic Publishing. $275 \mathrm{p}$.

DEFRA, 2002. Development of competitiveness indicators for the food chain industries, DEFRA Working Paper, Economics (international) Division, UK.

Drescher, K. \& Maurer, O. 1999. Competitiveness in the European dairy industries. Agribusiness 15: 163-77.

Dries L., Fałkowski J., Malak-Rawlikowska A. \& Milczarek-Andrzejewska D. 2011. Public policies and private initiatives in transition: evidence from the Polish dairy sector. Post-Communist Economies 23: 219-236.

Horn, E.-J. 1985. Internationale Wettbewerbsfähigkeit von Landern. WiST-Wirtschaftswissenschaftliche Studien 7: 323-329.

Hayami, H. \& Ruttan, V. 1991. Agricultural Development -An International Perspective. Baltimore: The John Hopkins University Press. $367 \mathrm{p}$.

Jansik, C., Irz, X., \& Kuosmanen, N. 2014. Competitiveness of Northern European dairy chains, MTT Taloustutkimus Publications 116, Helsinki: MTT Agrifood Research Finland. 160 p.

Krievina A. 2012. Value added creation problems and its increase possibilities in dairy sector. PhD. Thesis, Faculty of Economics, Latvia University of Agriculture, Jelgava. $131 \mathrm{p}$.

Krugman, P. 1994. Competitiveness: A dangerous obsession. Foreign Affairs 73: 28-44.

Latruffe, L. 2010. Competitiveness, productivity and efficiency in the agricultural and agri-food sectors. OECD Food, Agriculture and Fisheries Working Papers, No 30, Paris: OECD Publishing.

O'Donnell, C.J. 2012. Nonparametric estimates of the components of productivity and profitability change in U.S. agriculture. American Journal of Agricultural Economics 94: 873-890.

O'Mahony M. \& Timmer, M. P. 2009. Output, input, and productivity measurement at the industry level: the EU KLEMS database. Economic Journal 119: F374-F403.

Sipiläinen T., Kuosmanen T., \& Kumbhakar S.C. 2008. Measuring productivity differentials -An application to milk production in Nordic countries. 12th Congress of the European Association of Agricultural Economics, Ghent, Belgium. 7 p.

Viira A., Põder A. \& Värnik R. 2009. The factors affecting the motivation to exit farming -evidence from Estonia, Food Economics - Acta Agriculturae Scandinavica, Section C, 63: 156-172. 


\section{Appendix}

Detail of visits in individual countries

\begin{tabular}{|c|c|c|c|}
\hline \multirow{2}{*}{ Country } & \multirow{2}{*}{ Time of visits } & \multicolumn{2}{|c|}{ Number of visited and interviewed } \\
\hline & & dairy farms & other stakeholder organisations \\
\hline Estonia & May 2011 & 3 & 8 \\
\hline Latvia & May 2011 & 2 & 4 \\
\hline Lithuania & March 2012 & 5 & 4 \\
\hline Poland & April \& May 2012 & 5 & 4 \\
\hline Germany & April 2013 & 5 & 4 \\
\hline Denmark & April \& May 2013 & 6 & 6 \\
\hline Sweden & May 2013 & 4 & 2 \\
\hline Finland & 2013-2014 & 4 & 6 \\
\hline
\end{tabular}

Source of data: authors 